\title{
Pengaruh Kualitas Pelayanan dan Kepuasan Konsumen terhadap Loyalitas Pelanggan pada PT. Satria Antaran Prima
}

\author{
${ }^{1}$ Hendrian Yonata , ${ }^{2}$ Priski Setiawan, ${ }^{3}$ Ruby Santamoko, ${ }^{4}$ Diah Asdiany \\ 1,2,3 STAB Dharma Widya \\ ${ }^{4,5}$ Institut Agama Islam Negeri (IAIN) PalopoPalopo

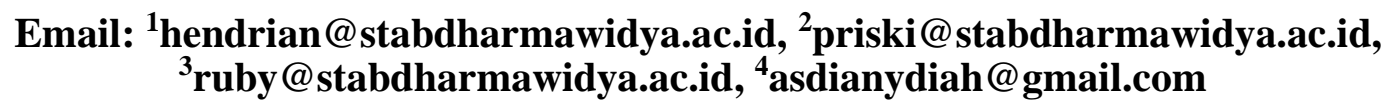

Article History:

Received: 08-Nopember-2020; Received in Revised: 10-Nopember-2020; Accepted: 17-Nopember-2020

\begin{abstract}
ABSTRAK
Pengaruh Kualitas Pelayanan dan Kepuasan Konsumen terhadap Loyalitas Pelanggan yang dilakukan perusahaan sangatlah mempengaruhi penjualan dan peluang untuk memperoleh laba yang merupakan dasar untuk mengembangkan perusahaan dimasa yang akan datang. Untuk mencapai tujuannya, perusahaan harus mengetahui bagaimana cara meningkatkan kepuasan konsumen yang efektif dan efiesien dengan menggunakan segala kelebihan dari sumber daya yang dimiliki dan menghilangkan atau sekurang-kurangnya mengurangi kelemahan-kelemahan sehingga dapat bersaing dengan perusahaan lain. Model penelitian yang digunakan untuk menganalisis penelitian mengenai Pengaruh Kualitas Pelayanan dan Kepuasan Konsumen terhadap Loyalitas Pelanggan yaitu menggunakan metode deskriptif, dimana menjelaskan tentang bagaimana data akan dikumpulkan, diolah dan dianalisis untuk suatu pembuktian dan pengujian dalam mencapai suatu tujuan. Model penelitian deskriptif adalah untuk membuat deskripsi atau gambaran secara sistematis dan akurat sifat-sifat yang berhubungan antara fenomena yang akan diteliti. Dalam melakukan penelitian mengenai masalah yang akan dibahas, metode yang dipilih adalah metode penelitian survei, dimana dalam metode ini informasi atau data-data dikumpulkan dari setiap responden melalui kuesioner. Penelitian dilakukan pada PT. Satria Antaran Prima, untuk mengetahui pengaruh variabel kualitas layanan (X1) dan kepuasaan konsumen (X2) terhadap loyalitas pelanggan (Y).
\end{abstract}

Kata kunci: Kualitas Pelayanan; Kepuasan Konsumen; Loyalitas Pelanggan.

ABSTRACT

The influence of Service Quality and Customer Satisfaction on Customer Loyalty by the company significantly affects sales and opportunities to earn profits, which are the basis for developing the company. To achieve its goals, the company must know how to increase customer satisfaction effectively and efficiently by using all the advantages of its resources and eliminating or at least reducing weaknesses to compete with other companies. The research model used to analyze research on the Effect of Service Quality and Customer Satisfaction on Customer Loyalty uses descriptive methods, which describe how data will be collected, processed, and analyzed for proof and testing in achieving a goal. A descriptive research model is to make a systematic and accurate description or description of the properties related to the phenomena to be studied. In researching the issues to be discussed, the method chosen is a survey research method, wherein this method information or data is collected from each respondent through a questionnaire. The research was conducted at PT. Satria Antaran Prima, to determine the effect of service quality variables (X1) and customer satisfaction (X2) on customer loyalty (Y). 


\section{Keywords: Service quality; Consumer Satisfaction; Customer loyalty.}

\section{PENDAHULUAN}

Dalam era globalisasi saat ini, dunia usaha merupakan salah satu pelaku utama pembangunan ekonomi dalam rangka meningkatkan tingkat pendapatan dan pembangunan masyarakat, untuk lebih menyejahterahkan rakyat dan mencapai masyarakat adil,makmur dan sejahtera, baik moril maupun materil. Pesatnya pembangunan serta banyaknya perusahaan yang ikut ambil bagian didalamnya akan berdampak sangat baik terhadap aspek social, dan aspek ekonomi, maka semakin dibutuhkan keberadaan perusahaan jasa. Seiring dengan pesatnya perkembangan dunia usaha menyebabkan perusahaan-perusahaan saling bersaing untuk mendapatkan jumlah konsumen terbesar, berusaha mencari peluang untuk memperluas pangsa pasarnya, agar dapat memenangkan persaingan tersebut ataupun untuk meningkatkan penjualan dan tujuan-tujuan lainnya. Salah satunya, dibidang jasa pengiriman. Jasa pengiriman ini sangat dibutuhkan dimana dalam menjalankan aktifitas dan memperlancar kegiatan bisnis. Untuk mempermudah ketika terjadi pengiriman domestic dan internasional. Karena semakin meningkatnya kebutuhan masyarakat terhadap jasa pengiriman maka semakin menjamur pula berdirinya perusahaan yang bergerak dibidang jasa pengiriman. Pelayanan adalah salah satu cara untuk menarik perhatian konsumen sehingga konsumen dapat merasakan kepuasan yang dapat membentuk perusahaan secara positif di mata konsumen. Berbagai fasilitas disunguhkan untuk memanjakan konsumen yang datang ke PT.Satria Antaran Prima. Setiap perusahaan dalam usahanya untuk tercapainya tujuan dan sasaran yang diinginkan yaitu meningkatkan kepuasan konsumen serta meningkatkan pangsa pasar dan menghadapi setiap pesaing yang ada, serta sistematika pemasaran juga penjualan yang digunakan dan yang terpenting kebijaksanaan-kebijaksanaan, pemasaran yang dilakukan oleh perusahaan seperti : Bagaimana Pengaruh Kualitas Pelayanan dan Kepuasan Konsumen terhadap Loyalitas Pelanggan oleh perusahaan. Pengaruh Kualitas Pelayanan dan Kepuasan Konsumen terhadap Loyalitas Pelanggan yang dilakukan perusahaan sangatlah mempengaruhi penjualan dan peluang untuk memperoleh laba yang merupakan dasar untuk mengembangkan perusahaan dimasa yang akan datang. Untuk mencapai tujuannya, perusahaan harus mengetahui bagaimana cara meningkatkan kepuasan konsumen yang efektif dan efiesien dengan menggunakan segala kelebihan dari sumber daya yang dimiliki dan menghilangkan atau sekurang-kurangnya mengurangi kelemahan-kelemahan sehingga dapat bersaing dengan perusahaan lain.

\section{METODE}

Model penelitian yang digunakan untuk menganalisis penelitian mengenai Pengaruh Kualitas Pelayanan dan Kepuasan Konsumen terhadap Loyalitas Pelanggan yaitu menggunakan metode deskriptif, dimana menjelaskan tentang bagaimana data akan dikumpulkan, diolah dan dianalisis untuk suatu pembuktian dan pengujian dalam mencapai suatu tujuan. Model penelitian deskriptif adalah untuk membuat deskripsi atau gambaran secara sistematis dan akurat sifat-sifat yang berhubungan antara fenomena yang akan diteliti. Dalam melakukan penelitian mengenai masalah yang akan dibahas, metode yang dipilih adalah metode penelitian survei, dimana dalam metode ini informasi atau data-data dikumpulkan dari setiap responden melalui kuesioner. Operasional variabel adalah suatu konsep yang diubah menjadi variabel yang dapat diukur. Jadi variabel yang digunakan dalam penelitian ini harus diubah menjadi definisi operasional variabel dengan tujuan untuk memberikan batasan dan penjelasan dalam rangka membatasi analisis yang lebih lanjut.

Tabel 1.1 Operasional Variabel

\begin{tabular}{|l|l|l|l|}
\hline \multicolumn{1}{|c|}{ Variable } & \multicolumn{1}{|c|}{ Sub Variabel } & \multicolumn{1}{|c|}{ Indiator } & Keterangan \\
\hline Kualitas & 1. Kehandalan & 1. Waktu Pengiriman & \\
Pelayanan(X1) & 2. Jaminan & 2. Keakuratan & Ordinal \\
& 3. Bukti Fisik & 3. Menangapi Keluhan & \\
\hline
\end{tabular}




\begin{tabular}{|c|c|c|c|}
\hline & $\begin{array}{l}\text { 4. Kepedulian } \\
\text { 5. Kesigapan }\end{array}$ & $\begin{array}{l}\text { 4. Jaminan } \\
\text { 5. Fasilitas Fisik } \\
\text { 6. Penampilan } \\
\text { 7. Pelayanan } \\
\text { 8. Kesungguhan } \\
\text { 9. Perhatian dan Pemenuhan } \\
\text { Kebutuhan } \\
\text { 10. Pelayanan cepat }\end{array}$ & \\
\hline $\begin{array}{l}\text { Kepuasan } \\
\text { Pelanggan (X2) }\end{array}$ & $\begin{array}{ll}\text { 1. } & \text { Kualitas Jasa } \\
\text { 2. Kemudahan Dalam } \\
\text { Pembayaran } \\
\text { 3. Penilaian Konsumen } \\
\text { 4. Keterbukaan Informasi } \\
\text { 5. Kemampuan } \\
\text { Berkomunikasi }\end{array}$ & $\begin{array}{l}\text { 1. Kualitas Jasa } \\
\text { 2. Kepercayaan Konsumen } \\
\text { 3. Informasi Pembayaran } \\
\text { 4. Perhitungan Administrasi } \\
\text { 5. Pelayanan dengan Harga Sesuai } \\
\text { 6. Keyakinan Pelanggan } \\
\text { 7. Informasi Jasa } \\
\text { 8. Informasi Barang } \\
\text { 9. Ramah Dalam Menjelaskan } \\
\text { 10. Memahami Setiap Keinginan }\end{array}$ & Ordinal \\
\hline $\begin{array}{l}\text { Loyalitas } \\
\text { Pelanggan } \\
\text { (Y) }\end{array}$ & $\begin{array}{l}\text { 1. Melakukan Pembelian } \\
\text { Ulang } \\
\text { 2. Merekomendasikan } \\
\text { 3. Kekebalan Pesaing } \\
\text { 4. Jangka Panjang } \\
\text { Pembelian } \\
\text { 5. Hubungan Baik }\end{array}$ & $\begin{array}{l}\text { 1. Jasa Pengiriman Secara Teratur } \\
\text { 2. Mengingat } \\
\text { 3. Merekomendasikan Jasa } \\
\text { 4. Menginformasikan } \\
\text { 5. Jasa Pengiriman } \\
\text { 6. Pesaing } \\
\text { 7. Situasi Mendatang } \\
\text { 8. Tetap Menggunakan } \\
\text { 9. Hubungan } \\
\text { 10. Menjalin Kounikasi }\end{array}$ & Ordinal \\
\hline
\end{tabular}

Teknik pengumpulan data merupakan langkah yang paling strategis dalam penelitian karena tujuan dari penelitian adalah mendapatkan data. Tanpa mengetahui teknik pengumpulan data, maka peneliti tidak akan mendapatkan data yang memenuhi standar data yang ditetapkan. Dalam usaha mengumpulkan data yang akurat dan valid, maka penulis menggunakan teknik pengumpulan data yaitu :

a. Penelitian Lapangan

Penelitian ini dilakukan dengan cara meninjau langsung ke perusahaan yang dalam penelitian ini adalah PT. Satria Antaran Prima selaku objek penelitian. Penelitian ini dilakukan untuk mengumpulkan data primer dengan :

1) Wawancara (interview) yaitu melakukan wawancara Iangsung terhadap responden yang dalam hal ini adalah karyawan, hal ini dimaksudkan melalui percakapan dua arah atas inisiatif pewawancara demi memperoleh informasi dan responden.

2) Dokumentasi yaitu mendapatkan data tertulis yang dibutuhkan, yang berasal dan dokumen dan catatan-catatan perusahaan seperti : jumlah karyawan, besarnya gaji dan upah yang diberikan, serta data lainnya yang dibutuhkan dalam penelitian ini.

3) Kuesioner (angket) yaitu pengumpulan data melalui daftar pertanyaan yang disiapkan masingmasing responden.

b. Penelitian Kepustakaan, yaitu penelitian yang bertujuan untuk memperoleh konsep dan landasan teori dengan mempelajari berbagai literature, buku, dan dokumen yang berkaitan dengan objek pembahasan.

Sumber data adalah tempat didapatkannya data yang diinginkan. Pengetahuan tentang sumber data merupakan hal yang penting untuk diketahui agar tidak terjadi kesalahan dalam memilih sumber data yang sesuai dengan tujuan penelitian. Dalam penelitian ini untuk mendapatkan data-data yang relevan, maka digunakan sumber-sumber data sebagai berikut: 


\section{1) Data Primer}

Yaitu sumber data penelitian yang diperoleh langsung dari sumber asli (tidak melalui media perantara). Data primer secara khusus dikumpulkan untuk dapat menjawab pertanyaan penelitian. Untuk memperolehnya penelitian ini melakukan penyebaran kuesioner yang akan diedarkan dan kemudian di isi oleh responden.

2) Data Sekunder

Yaitu merupakan sumber data penelitian yang diperoleh penulis secara tidak langsung melalui media perantara (diperoleh dan dicatat oleh pihak lain). Data sekunder yang digunakan dalam penelitian ini berupa bahan dari buku dan bahan referensi lainnya guna menyempurnakan penulisan.

\section{HASIL DAN PEMBAHASAN}

\section{Penyajian Data Berdasar Karakteristik Responden}

Karakteristik responden memberikan gambaran yang mengukur dengan skala nominal yang menunjukkan besarnya frekuensi absolut dan persentase jenis kelamin, usia, pendidikan terakhir dan pekerjaan. Objek dalam penelitian ini adalah konsumen yang menggunakan produk PT. Satria Antaran Prima. Sampel yang di ambil berjumlah 100 responden.

\section{Responden Berdasarkan Jenis Kelamin}

Berdasarkan hasil penelitian yang telah dilakukan, diperoleh data jenis kelamin responden sebagai berikut:

\section{Tabel 1.2 Jenis Kelamin Responden}

\begin{tabular}{|c|c|c|}
\hline Jenis Kelamin & Absolut & Persentase \\
\hline Laki - laki & 68 & $68 \%$ \\
\hline Perempuan & 32 & $32 \%$ \\
\hline Jumlah & 100 & $100 \%$ \\
\hline
\end{tabular}

Sumber : Data Primer yang diolah Ms. Excell 2017

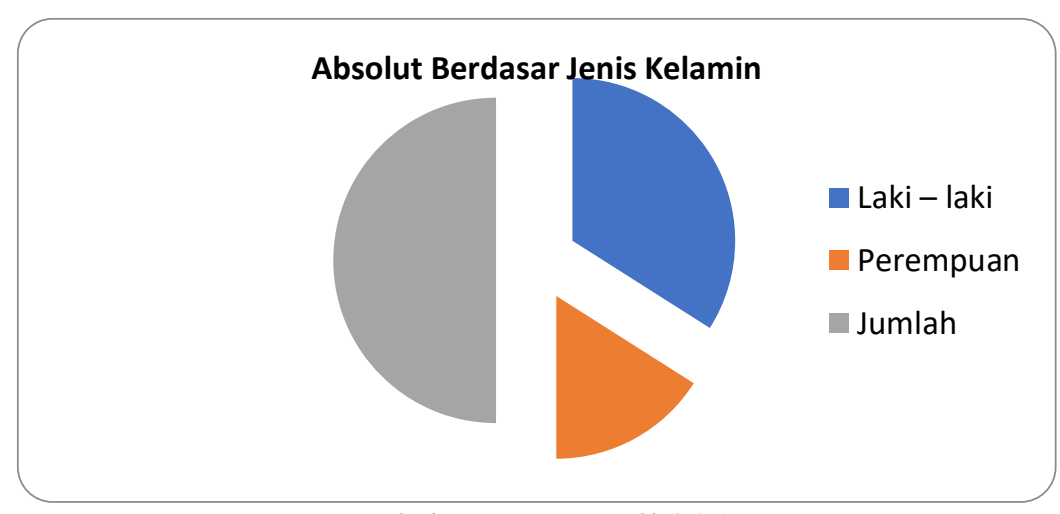

Diolah : Ms. Excell 2017

Pada tabel 1.2 dapat dilihat bahwa jumlah responden berdasarkan jenis kelamin terbanyak lakilaki yaitu sebanyak 68 orang atau sebesar $68 \%$ yang menggunakan jasa kualitas layanan SAP dalam bidang kargo dan pengiriman, sedangkan sisanya sebanyak 32 orang atau sebesar $32 \%$ oleh jenis kelamin perempuan yang menggunakan jasa kulitas layanan SAP dalam bidang kargo dan pengiriman.

\section{Responden Berdasarkan Usia Responden} berikut:

Berdasarkan hasil penelitian yang telah dilakukan, diperoleh data usia responden sebagai 
Tabel 1.3 Usia Responden

\begin{tabular}{|c|c|c|}
\hline Kategori & Absolut & Persentase \\
\hline $20-30$ Tahun & 7 & $7 \%$ \\
\hline $31-40$ Tahun & 21 & $21 \%$ \\
\hline Lebih dari 40 Tahun & 72 & $72 \%$ \\
\hline Jumlah & 100 & $100 \%$ \\
\hline
\end{tabular}

Sumber : Data Primer yang diolah Ms. Excell 2017

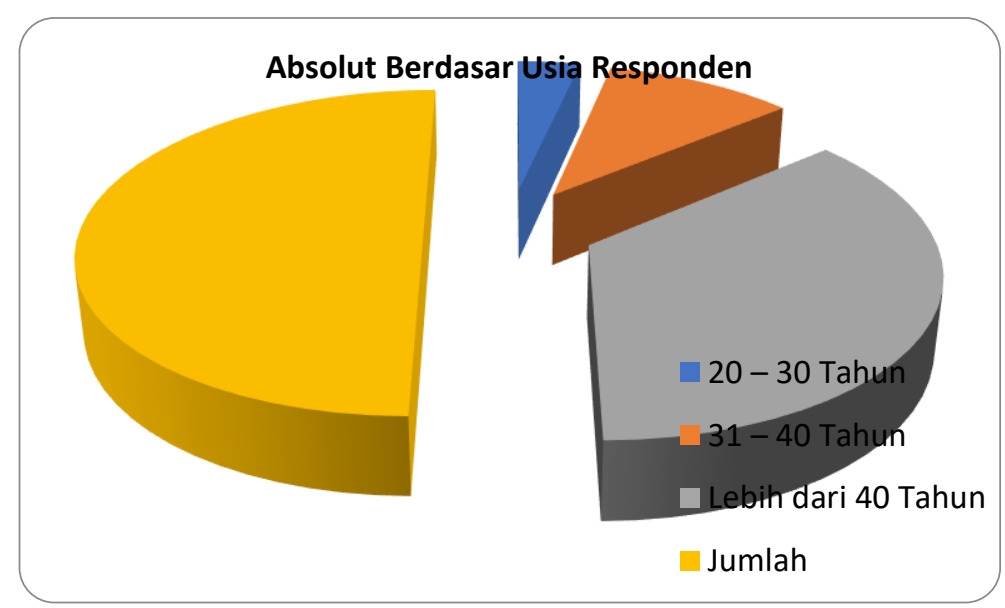

Diolah : Ms. Excell 2017

Pada tabel 1.3 dapat dilihat bahwa data responden menurut usia, disini terlihat yang lebih mendominasi adalah usia lebih dari 40 tahun yaitu sebesar 72 responden atau sebesar $72 \%$ yang memiliki loyalitas pelanggan dalam memakai jasa pelayanan SAP yang berkualitas dari sejak awal tidak pindah kepada pesaing lain sehingga konsumen mencapai kepuasaan. Lalu pada urutan kedua yaitu kisaran usia 31 - 40 tahun sebanyak 21 responden atau sebesar $21 \%$ yang ikut memakai jasa pelayanan SAP yang berkualitas dalam mencapai kepuasaan. Kemudian pada kisaran usia 20 - 30 tahun sebanyak 7 responden atau sebesar $7 \%$ yang ikut memakai jasa pelayanan SAP yang berkualitas dalam mencapai kepuasaan, karena rekomendasi informasi dari pengguna jasa layanan yang mencapai kepuasaan.

\section{Responden Berdasarkan Pendidikan Terakhir}

Berdasarkan hasil penelitian yang telah dilakukan, diperoleh data pendidikan terakhir responden sebagai berikut:

\section{Tabel 1.4 Pendidikan Terakhir}

\begin{tabular}{|c|c|c|}
\hline Pendidikan & Absolut & Persentase \\
\hline SMU & 45 & $45 \%$ \\
\hline Diploma & 21 & $21 \%$ \\
\hline S1 & 30 & $30 \%$ \\
\hline S2 & 4 & $4 \%$ \\
\hline S3 & - & - \\
\hline Jumlah & 100 & $100 \%$ \\
\hline
\end{tabular}

Sumber : Data Primer yang diolah 2017 


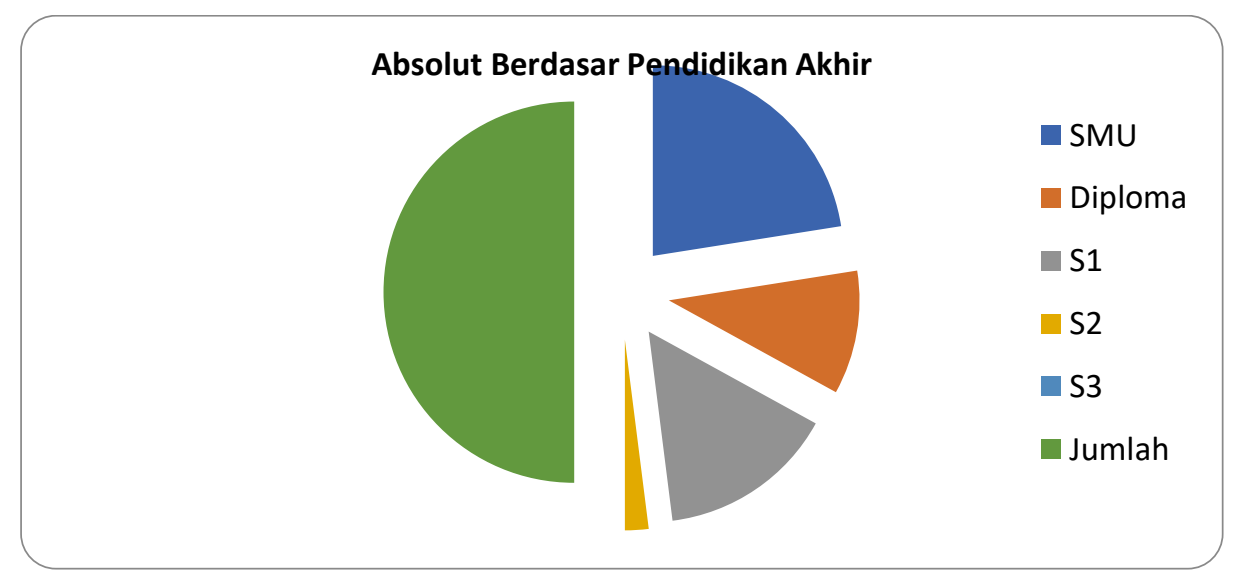

Diolah : Ms. Excell 2017

Pada tabel 1.4 dapat dilihat bahwa jumlah responden berdasarkan jenjang pendidikan terakhir terbesar adalah pendidikan terakhir SMU sebanyak 45 orang atau $45 \%$ yang menjadi pengguna jasa layanan SAP dalam bidang kargo dan pengiriman, urutan kedua responden dengan pendidikan terakhir Diploma sebanyak 21 orang atau $21 \%$, urutan ketiga responden dengan pendidikan terakhir S1 sebanyak 30 orang atau 30\%, urutan keempat responden dengan pendidikan terakhir S2 sebanyak 4 orang atau sebesar $4 \%$, namun pada pendidikan terkahir S3 tidak ada sejumlah responden yang memiliki pendidikan terakhir jenjang tersebut.

\section{Responden Berdasarkan Pekerjaan} berikut :

Berdasarkan hasil penelitian yang telah dilakukan, diperoleh data pekerjaan responden sebagai

Tabel 1.5 Pekerjaan

\begin{tabular}{|c|c|c|}
\hline Kategori & Absolut & Persentase \\
\hline Pegawai Negeri & 10 & $10 \%$ \\
\hline Pegawai Swasta & 57 & $57 \%$ \\
\hline Wiraswasta & 33 & $33 \%$ \\
\hline Jumlah & 100 & $100 \%$ \\
\hline
\end{tabular}

Sumber : Data Primer yang diolah 2013

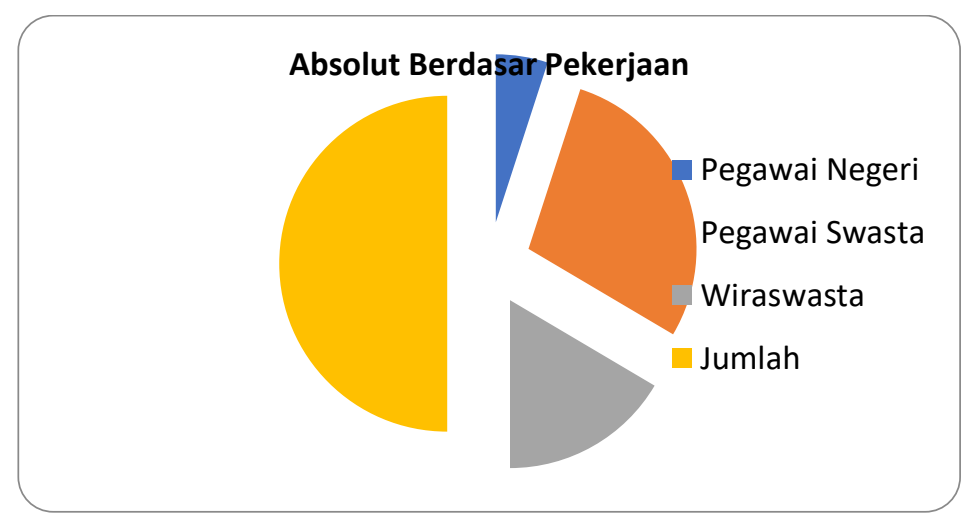

Diolah : Ms. Excell 2013

Pada tabel 1.5 dapat dilihat bahwa jumlah responden berdasarkan pekerjaan tersebar pada pegawai negeri sebanyak 10 orang atau sebesar $10 \%$ yang menggunakan jasa layanan SAP, pegawai swasta sebanyak 57 orang atau sebesar 57\% yang menggunakan jasa layanan SAP, dan wiraswasta sebanyak orang atau sebesar 33 orang atau sebesar 33\% yang menggunakan jasa layanan SAP. 


\section{Analisis Deskriptif Variabel}

Pada bagian ini akan dilakukan analisis deskriptif data kuesioner yang sudah disebarkan pada 100 responden. Analisis kuesioner ini digunakan untuk menguji seberapa baik data yang digunakan melalui indikator sebagai pengukur. Adapun Deskriptif variabel Tabel 4.2.1 Rekapitulasi Kuisioner Kualitas Pelayanan (X1) dan Tabel 4.2.2 Rekapitulasi Kuisioner Kepuasan Konsumen (X2) terhadap Tabel 4.2.3 Rekapitulasi KuisionerLoyalitas Pelanggan (Y) dan hasil Kuisioner terlampir. Untuk mengolah data dari deskriptif hasil kuisioner kemudian diolah menurut presentase frekuensi jawaban kuisioner dari instrumen penelitian Sangat Setuju, Setuju, Ragu-ragu Tidak Setuju, dan Sangat Tidak Setuju dari sejumlah 100 responden.

\section{Tanggapan Responden Mengenai Kualitas Pelayanan (X1)}

Tujuan dari kualitas pelayanan untuk menciptakan kepuasan pelanggan, dan juga membangun kesetiaan pelanggan, dimana kualitas pelayanan merupakan tingkat perbandingan antara harapan pelanggan atas pelayanan yang dilakukan oleh perusahaan dengan pelayanan yang mereka terima secara nyata. elayanan yang diterima pelanggan secara nyata dibuktikan dengan adanya fasilitas pelayanan yang peduli terhadap kebutuhan konsumen, dengan kehandalan dan keakuratan waktu pengiriman, serta sigap dalam memberikan pelayanan yang prima dengan jaminan baik secara produk atau layanan yang berkualitas. Adapun penetapan kualitas layanan dengan indikator kehandalan, jaminan, bukti fisik, kepedulian dan sigap. Berikut ini ditampilkan jawaban indikator dari tanggapan responden atas sejumlah pernyataan atau pertanyaan dalam table 4.2.1 Frekuensi Variabel X1 Kualitas Layanan.

Tabel 1.6 Frekuensi Variabel X1 Kualitas Pelayanan

\begin{tabular}{|c|c|c|c|c|c|c|}
\hline $\mathrm{P}$ & 5 & 4 & 3 & 2 & 1 & $\mathrm{~L}$ \\
\hline 1 & 23 & 65 & 11 & 1 & 0 & 100 \\
\hline & $23 \%$ & $65 \%$ & $11 \%$ & $1 \%$ & $0 \%$ & $100 \%$ \\
\hline & 7 & 29 & 50 & 14 & 0 & 100 \\
\hline 3 & $7 \%$ & $29 \%$ & $50 \%$ & $14 \%$ & $0 \%$ & $100 \%$ \\
\hline & 23 & 72 & 5 & 0 & 0 & 100 \\
\hline 4 & $23 \%$ & $72 \%$ & $5 \%$ & $0 \%$ & $0 \%$ & $100 \%$ \\
\hline & 29 & 68 & 3 & 0 & 0 & 100 \\
\hline 5 & $29 \%$ & $68 \%$ & $3 \%$ & $0 \%$ & $0 \%$ & $100 \%$ \\
\hline & 26 & 73 & 1 & 0 & 0 & 100 \\
\hline 6 & $26 \%$ & $73 \%$ & $1 \%$ & $0 \%$ & $0 \%$ & $100 \%$ \\
\hline 7 & 26 & 73 & 1 & 0 & 0 & 100 \\
\hline & $26 \%$ & $73 \%$ & $1 \%$ & $0 \%$ & $0 \%$ & $100 \%$ \\
\hline 8 & 23 & 65 & 11 & 1 & 0 & 100 \\
\hline & $23 \%$ & $65 \%$ & $11 \%$ & $1 \%$ & $0 \%$ & $100 \%$ \\
\hline 9 & 27 & 62 & 10 & 1 & 0 & 100 \\
\hline & $27 \%$ & $62 \%$ & $10 \%$ & $1 \%$ & $0 \%$ & $100 \%$ \\
\hline 10 & 13 & 34 & 40 & 12 & 1 & 100 \\
\hline $\mathrm{n}$ & $13 \%$ & $34 \%$ & $40 \%$ & $12 \%$ & $1 \%$ & $100 \%$ \\
\hline & 13 & 33 & 40 & 13 & 1 & 100 \\
\hline & 210 & 574 & 172 & 42 & 2 & 1000 \\
\hline & $21 \%$ & $57 \%$ & $17 \%$ & $4 \%$ & $0 \%$ & $100 \%$ \\
\hline
\end{tabular}

Sumber : Data diolah dengan microsoft excel 2013 
Berdasarkan hasil penyajian data di atas jawaban tanggapan indikator tabel 1.6. variabel X1 Kualitas Pelayanan dengan 10 pernyataan atau pertanyaan dan 100 responden. Disimpulkan responden tertinggi menjawab setuju $21 \%$, sangat setuju $57 \%$, kurang setuju $17 \%$, tidak setuju $4 \%$ dan sangat tidak setuju 0\%. Bahwa pernyataan dari lembar kuesioner sesuai secara empirik tentang indikator kehandalan, jaminan, bukti fisik, kepedulian dan sigap dengan jawaban setuju sebesar $57 \%$ untuk menuju kualitas pelayanan.

\section{Tanggapan Responden Mengenai Kepuasaan Konsumen (X2)}

Kepuasan merupakan suatu perasaan yang terdapat pada setiap konsumen dalam menilai produk atau jasa yang digunakan dan perasaan tersebut membandingkan harapan dan kinerja yang akhirnya akan meningkatkan atau menurunkan ekspektasi dan nilai kepuasan para konsumen tersebut. Ketika konsumen merasa puas akan pelayanan yang didapatkan pada saat proses transaksi dan juga puas akan barang atau jasa yang mereka dapatkan, besar kemungkinan mereka akan kembali lagi dan melakukan pembelian-pembelian yang lain dan juga akan merekomendasikan kepada teman-teman dan keluarganya tentang perusahaan tersebut dan produk-produknya. Kepuasaan dalam kualitas produk dan pelayanan akan mampu membuat konsumen merasa diperhatikan akan kebutuhannya sehingga konsumen menjadi terpuaskan.

Adapun penetapan kepuasaan konsumen dilihat dengan indikator berkualitasnya jasa atau produk yang diberikan oleh perusahaan dalam memenuhi kebutuhan konsumen akan menimbulkan kepercayaan dan keyakinan konsumen, untuk menuju kepuasaan konsumen dibutuhkan keramahan dalam memberikan informasi barang atau jasa sehingga keinginan konsumen mudah dipahami, lalu adanya kemudahan dalam pembayaran dan penyesuaian informasi harga. Berikut ini ditampilkan jawaban indikator dari tanggapan responden atas sejumlah pernyataan atau pertanyaan dalam table 4.2.2 Frekuensi Variabel X2 Kepuasaan Konsumen.

Tabel 1.7. Frekuensi Variabel X2 Kepuasaan Konsumen

\begin{tabular}{|c|c|c|c|c|c|c|}
\hline $\mathrm{P}$ & 5 & 4 & 3 & 2 & 1 & $\mathrm{~L}$ \\
\hline 1 & 3 & 29 & 48 & 19 & 1 & 100 \\
\hline & $3 \%$ & $29 \%$ & $48 \%$ & $19 \%$ & $1 \%$ & $100 \%$ \\
\hline 2 & 28 & 49 & 15 & 8 & 0 & 100 \\
\hline & $28 \%$ & $49 \%$ & $15 \%$ & $8 \%$ & $0 \%$ & $100 \%$ \\
\hline 3 & 7 & 28 & 47 & 17 & 1 & 100 \\
\hline & $7 \%$ & $28 \%$ & $47 \%$ & $17 \%$ & $1 \%$ & $100 \%$ \\
\hline 4 & 6 & 35 & 43 & 15 & 1 & 100 \\
\hline & $6 \%$ & $35 \%$ & $43 \%$ & $15 \%$ & $1 \%$ & $100 \%$ \\
\hline 5 & 10 & 32 & 42 & 16 & 0 & 100 \\
\hline & $10 \%$ & $32 \%$ & $42 \%$ & $16 \%$ & $0 \%$ & $100 \%$ \\
\hline 6 & 12 & 30 & 42 & 16 & 0 & 100 \\
\hline & $12 \%$ & $30 \%$ & $42 \%$ & $16 \%$ & $0 \%$ & $100 \%$ \\
\hline 7 & 9 & 29 & 48 & 14 & 0 & 100 \\
\hline & $9 \%$ & $29 \%$ & $48 \%$ & $14 \%$ & $0 \%$ & $100 \%$ \\
\hline 8 & 15 & 26 & 40 & 17 & 2 & 100 \\
\hline & $15 \%$ & $26 \%$ & $40 \%$ & $17 \%$ & $2 \%$ & $100 \%$ \\
\hline 9 & 3 & 29 & 48 & 19 & 1 & 100 \\
\hline & $3 \%$ & $29 \%$ & $48 \%$ & $19 \%$ & $1 \%$ & $100 \%$ \\
\hline 10 & 28 & 49 & 15 & 8 & 0 & 100 \\
\hline & $28 \%$ & $49 \%$ & $15 \%$ & $8 \%$ & $0 \%$ & $100 \%$ \\
\hline
\end{tabular}




\begin{tabular}{|c|c|c|c|c|c|c|}
$\mathrm{n}$ & 121 & 336 & 388 & 149 & 6 & 1000 \\
\hline & $12 \%$ & $34 \%$ & $39 \%$ & $15 \%$ & $1 \%$ & $100 \%$ \\
\hline
\end{tabular}

Sumber : Data diolah dengan microsoft excel 2013

Berdasarkan hasil penyajian data di atas jawaban tanggapan indikator tabel 1.7. variabel X2 Kepuasaan konsumen dengan 10 pernyataan atau pertanyaan dan 100 responden. Disimpulkan responden menjawab setuju 34\%, sangat setuju 12\%, dan kurang setuju 39\% dikarenakan setiap konsumen memiliki pemahaman dan penilaian tersendiri yang berdasarkan pengalaman atas produk atau jasa yang dibutuhkan sesuai dengan harapan untuk mendapatkan yang berkualitas, tidak setuju $15 \%$ dan sangat tidak setuju 1\%. Bahwa pernyataan dari lembar kuesioner sesuai secara empirik tentang indikator kualitas jasa, kemudahan membayar, penilaian konsumen, keterbukaan informasi dan kemampuan dalam berkomunikasi.

\section{Tanggapan Responden Mengenai Loyalitas Pelanggan (Y)}

Loyalitas pelanggan sangat penting bagi perusahaan karena konsumen yang loyal akan memberikan banyak manfaat bagi perusahaan. Apabila perusahaan dapat menumbuhkan loyalitas, maka dengan sendirinya pelanggan yang loyal akan memberikan kelebihan dan kebaikan bagi produk perusahaan. Ketika konsumen merasa puas akan pelayanan yang didapatkan pada saat proses transaksi dan juga puas akan barang atau jasa yang mereka dapatkan, besar kemungkinan mereka akan kembali lagi dan melakukan pembelian-pembelian yang lain dan juga akan merekomendasikan kepada teman-teman dan keluarganya tentang perusahaan tersebut dan produk-produknya.

Hasil dari pembelian kembali produk atau jasa yang dihasilkan dan kemudian merekomendasikan ke keluarga, teman atau rekan bisnisnya merupakan bentuk loyalitas pelanggan, karena pelanggan telah mencapai kepuasaan. Loyalitas konsumen pelanggan merupakan perilaku yang terkait dengan merek sebuah produk, termasuk kemungkinan memperbaharui kontrak merek dimasa yang akan datang, berapa kemungkinan keinginan pelanggan untuk meningkatkan citra positif suatu produk

Adapun penetapan loyalitas pelanggan dilihat dengan indikator melakukan jangka waktu pembelian yang berulang ulang dan merekomendasikan kepembeli lain, memiliki kekebalan terhadap pesaing dan menjaga hubungan baik dalam membentuk loyalitas pelanggan. Berikut ini ditampilkan jawaban indikator dari tanggapan responden atas sejumlah pernyataan atau pertanyaan dalam tabel 4.2.3 Frekuensi Variabel Y Loyalitas Pelanggan.

Tabel 1.8. Frekuensi Variabel X1 Loyalitas Pelanggan

\begin{tabular}{|c|c|c|c|c|c|c|}
\hline $\mathrm{P}$ & 5 & 4 & 3 & 2 & 1 & $\mathrm{~L}$ \\
\hline 1 & 13 & 33 & 40 & 13 & 1 & 100 \\
\hline & $13 \%$ & $33 \%$ & $40 \%$ & $13 \%$ & $1 \%$ & $100 \%$ \\
\hline 2 & 28 & 50 & 14 & 8 & 0 & 100 \\
\hline & $28 \%$ & $50 \%$ & $14 \%$ & $8 \%$ & $0 \%$ & $100 \%$ \\
\hline 3 & 23 & 65 & 11 & 1 & 0 & 100 \\
\hline & $23 \%$ & $65 \%$ & $11 \%$ & $1 \%$ & $0 \%$ & $100 \%$ \\
\hline 4 & 7 & 29 & 50 & 14 & 0 & 100 \\
\hline & $7 \%$ & $29 \%$ & $50 \%$ & $14 \%$ & $0 \%$ & $100 \%$ \\
\hline 5 & 15 & 35 & 36 & 14 & 0 & 100 \\
\hline & $15 \%$ & $35 \%$ & $36 \%$ & $14 \%$ & $0 \%$ & $100 \%$ \\
\hline 6 & 15 & 35 & 36 & 14 & 0 & 100 \\
\hline & $15 \%$ & $35 \%$ & $36 \%$ & $14 \%$ & $0 \%$ & $100 \%$ \\
\hline 7 & 15 & 26 & 40 & 17 & 2 & 100 \\
\hline
\end{tabular}




\begin{tabular}{|c|c|c|c|c|c|c|} 
& $15 \%$ & $26 \%$ & $40 \%$ & $17 \%$ & $2 \%$ & $100 \%$ \\
\hline 8 & 3 & 29 & 48 & 19 & 1 & 100 \\
\hline & $3 \%$ & $29 \%$ & $48 \%$ & $19 \%$ & $1 \%$ & $100 \%$ \\
\hline 9 & 28 & 49 & 15 & 8 & 0 & 100 \\
\hline & $28 \%$ & $49 \%$ & $15 \%$ & $8 \%$ & $0 \%$ & $100 \%$ \\
\hline 10 & 27 & 62 & 10 & 1 & 0 & 100 \\
\hline & $27 \%$ & $62 \%$ & $10 \%$ & $1 \%$ & $0 \%$ & $100 \%$ \\
\hline $\mathrm{n}$ & 174 & 413 & 300 & 109 & 4 & 1000 \\
\hline & $17 \%$ & $41 \%$ & $30 \%$ & $11 \%$ & $0 \%$ & $100 \%$ \\
\hline
\end{tabular}

Sumber : Data diolah dengan microsoft excel 2013

Berdasarkan hasil penyajian data di atas jawaban tanggapan indikator tabel 1.8. variabel Y Loyalitas Pelanggan dengan 10 pernyataan atau pertanyaan dan 100 responden. Disimpulkan responden menjawab setuju sebesar $41 \%$ karena hubungan baik dalam pelayanan yang ramah dan pengiriman yang sesuai waktu serta teratur akan membuat pelanggan melakukan pembelian berulang dan merekomendasikan konsumen untuk menjadi pelanggan tetap SAP, sangat setuju $17 \%$ yang menjelaskan pelanggan loyal terhadap produk atau jasa, dan kurang setuju $30 \%$ tidak setuju $11 \%$ dan sangat tidak setuju 0\%. Bahwa pernyataan dari lembar kuesioner sesuai secara empirik tentang loyalitas pelanggan yang melakukan pembelian berulang, berani merekomendasikan, tetap menggunakan produk atau jasa dalam jangka panjang dan menjaga hubungan baik.

\section{KESIMPULAN}

Penelitian dilakukan pada PT. SATRIA ANTARAN PRIMA, untuk mengetahui pengaruh variabel kualitas layanan (X1) dan kepuasaan konsumen (X2) terhadap loyalitas pelanggan (Y). Berdasarkan hasil analisis dan pembahasan, maka dapat diambil kesimpulan sebagai berikut :

a. Kualitas Layanan (X1) terhadap Loyalitas Pelanggan (Y)

1) Nilai t hitung $=9.957$, maka nilai $t$ hitung $>$ Nilai t tabel atau 9,957 $>1,66071$ dengan nilai signifikasi $0,000<0,05$.

2) Dari hasil uji parsial kualitas pelayanan (X1) terhadap loyaitas pelanggan (Y), H0 ditolak dan $\mathrm{H} 1$ diterima.

3) Menyatakan bahwa Ada pengaruh yang signifikan kualitas pelayanan (X1) terhadap variabel loyalitas pelanggan $(\mathrm{Y})$

4) Nilai Koefiesien determinasi $\left(\mathrm{R}^{2}\right)$ sebesar 0,507 yang memiliki pengertian bahwa pengaruh variabel bebas (trust) kualitas layanan (X1) terhadap variabel terikat (Partisifatif) Kepuasaan konsumen sebesar 0,498 atau sebesar 49,8\% sedangkan sisanya dipengaruhi variabel lain.

\section{b. Kepuasaan Konsumen (X2) terhadap Loyalitas Pelanggan (Y)}

1) Nilai t hitung $=11,361$, maka nilai t hitung $>$ Nilai t tabel atau 11,361 >1,66071 dengan nilai signifikasi $0,000<0,05$.

2) Dari hasil uji parsial kepuasaan konsumen (X1) terhadap loyaitas pelanggan (Y), H0 ditolak dan H1 diterima.

3) Menyatakan bahwa Ada pengaruh yang signifikan kepuasaan konsumen (X2) terhadap variabel loyalitas pelanggan $(\mathrm{Y})$

4) Nilai Koefiesien determinasi $\left(\mathrm{R}^{2}\right)$ sebesar 0,784 yang memiliki pengertian bahwa pengaruh variabel bebas (trust) ada pengaruh yang signifikan dan positif sebesar 0,784 atau sebesar 
78,4\% dari Kepuasaan Konsumen (X1) terhadap Loyalitas Pelanggan (Y) sedangkan sisanya $21,6 \%$ dipengaruhi dengan faktor lainnya

\section{c. Kualitas Layanan (X1) dan Kepuasaan Konsumen (X2) terhadap Loyalitas Pemanggan (Y)}

1) Nilai t hitung $=18,833$ maka nilai thitung $>$ Nilai $t$ tabel atau 18,833 $>1,663$ dengan nilai signifikasi $0,000<0,05$.

2) Dari hasil uji parsial kualitas layanan (X1) terhadap loyalitas pelanggan (Y), H0 ditolak dan H1 diterima.

3) Dari hasil uji parsial kepuasaan konsumen (X2) terhadap loyalitas pelanggan (Y), H0 ditolak dan $\mathrm{H} 2$ diterima.

4) Dari hasil uji simultan kualitas layanan (X1) dan kepuasaan konsumen (X2) terhadap loyalitas pelanggan (Y), $\mathrm{H} 0$ ditolak dan $\mathrm{H} 3$ diterima.

5) Hal ini menyatakan bahwa Ada pengaruh yang signifikan kualitas layanan (X1) dan kepuasaan konsumen (X2) terhadap variabel keputusan loyalitas pelanggan (Y), yaitu : dengan koefisein determinasi (R2) sebesar 0,844 atau sebesar 84,4\% sedangkan sisanya $11,6 \%$ dihubungkan dengan faktor lainnya. Dan menjelaskan ada pengaruh yang signifikan dan positif sebesar 0,886 atau sebesar 88,6\% dari Kualitas Layanan (X1) dan Kepuasaan Konsumen (X2) terhadap Loyalitas Pelanggan (Y) sedangkan sisanya 11,4\% dipengaruhi dengan faktor lainnya.

\section{Saran}

Berdasarkan hasil analisis dan kesimpulan penelitian ini, maka ada beberapa saran sebagai berikut:

a. Dari ketiga faktor atau variabel hasil uji koefesien determinasi kualitas layanan terhadap loyalitas pelanggan yang paling rendah, dikarenakan keterbatasan waktu penelitian besar harapan penulis untuk penulis selanjutnya agar melakukan penelitian lebih lanjut untuk memaksimalkan pengaruh kualitas layanan terhadap loyalitas pelanggan.

b. Secara empirik kepuasaan konsumen terhadap loyalitas pelanggan tergolong cukup baik terlihat dari uji parsial maupun koefesien determinasi dengan hasil yang tinggi, dengan ini pihak manajemen PT. Satria Antaran Prima harus lebih mempertahankan kepuasaan konsumen yang sudah baik .

Secara empirik kualitas layanan dan kepuasan konsumen terhadap loyalitas di PT. Satria Antaran Prima sangat baik terlihat nilai koefesien determinasi yaitu $84.4 \%$, dengan hasil yang baik itu berdasarkan dari variabel kualitas layanan dan kepuasaan konsumen, berjalan bersama secara maksimal memberikan pengaruh positif terhadap loyalitas pelanggan, dengan ini manajemen harus mempertahankan keseimbangan semua faktor yang mempengaruhi loyalitas pelanggan, agar perusahaan dapat berjalan dan berkembang memberikan keuntungan bagi semua karyawan dimasa yang akan datang.

\section{DAFTAR PUSTAKA}

Andrianto, S., \& Wijoyo, H. (2020). Rancang Bangun Sistem Informasi Siswa Berbasis Web di Sekolah Minggu Buddha Vihara Dharmaloka Pekanbaru. TIN: Terapan Informatika Nusantara, 1(2), 83-90.

Bramesta, \& Wijoyo, H. (2019). Perancangan Sistem Informasi Pengelolaan Data Warga Binaan Sosial Di UPT. Bina Laras Dinas Sosial Provinsi Riau. Jurnal Ilmu Komputer dan Bisnis, 10(2), 2226-2233. https://doi.org/10.47927/jikb.v10i2.170 
Cahyono, Y., Purwanto, A., Sukanta, F. N. A., Fitriaty, H. W., Sihotang, M., \& Sugianto, A. (2020). Impact Of Service Quality, University Image And Students Satisfaction Towards Student loyalty: Evidence From Indonesian Private Universities. Journal ofCriticalReviews, 7(19), 3916-3924.

Cahyono, Y., Jihadi, . M., Arifin, .Z., Purnamasari, . W., Musnaini, ., Wijoyo, . H., Fitriaty, ., Putra, . R. S., Putri, . R. A., Muliansyah, . D., Suryani, . P. \& Purwanto, . A. (2020) Do Servant Leadership Influence Market Performance? Evidence from Indonesian Pharmacy Industries. Systematic Reviews in Pharmacy, 11 (9), 439-451. doi:10.31838/srp.2020.9.62

Fahmi, K., Kurniawan, T., Cahyono, Y., \& Sena, A. (2020). Did Servant, Digital and Green Leadership Influence Market Performance? Evidence from Indonesian Pharmaceutical Industry. Systematic Reviews in Pharmacy, 11(9), 642-653.

Haudi, H. W., \& Cahyono, Y. (2020). Effect Of Product Innovation and Marketing Strategy on Consumer Purchase Decisions In Indonesia's Lightweight Roof Steel Industry. Journal of Critical Reviews, 7(13), 4147-4155.

Lukito, C. P. ., \& Setiawan, P. . (2020). Pengaruh Earning Per Share dan Return On Asset terhadap Harga Saham pada PT. Sepatu Bata Indonesia Tbk. Jurnal Ilmu Komputer Dan Bisnis, 11(2a), 63-71. https://doi.org/10.47927/jikb.v11i2a.258

Siagian, . A. O., Nufus, . K., Yusuf, . N., Supratikta, . H., Maddinsyah, . A., Muchtar, . A., Sari, . W. I., Sunarsi, . D., Akbar, . I. R., Arianto, . N., Purwanto, . A., Noryani, . \& Wijoyo, . H. (2020) A Systematic Literature Review of Education Financing Model in Indonesian School. Systematic Reviews in Pharmacy, 11 (10), 638-644. doi:10.31838/srp.2020.10.96

Sugandha, S. (2019). Pengaruh Lingkungan Kerja Dan Stress Kerja Terhadap Kinerja Karyawan (Studi Kasus di PT. KEONG NUSANTARA ABADI). Primanomics: Jurnal Ekonomi \& Bisnis, 17(2).

Sugandha Sugandha, Fx.Pudjo Wibowo, Hendra Hendra, 2019, Pengaruh Pelatihan Dan Pengembangan Sumber Daya Manusia Terhadap Prestasi Kerja Karyawan PT.Jembo Energindo, Dynamic Management Journal 3 (2).

Sunarsi, D., Wijoyo, H., Prasada, D., \& Andi, D. (2020, September). Pengaruh Lingkungan Kerja Terhadap Kinerja Karyawan Pada PT. Mentari Persada di Jakarta. In Seminar Nasional Manajemen, Ekonomi, Akuntansi (Vol. 5, No. 1, pp. 117-123).

Sunarsi, D. ., Rizka Akbar, I. ., Prasada, D. ., Kristianti, L. S. ., Muliani, H. S. ., Anjayani, N. S. ., \& Hendra, H. (2020). Pengaruh Kompetensi dan Pengembangan Karir terhadap Kinerja Karyawan pada PT. Berkah Cemerlang di Jakarta. Jurnal Ilmu Komputer Dan Bisnis, 11(2), 2465-2472. https://doi.org/10.47927/jikb.v11i2.251

Widiyanto, G., \& Sugandha, S. (2019). Analisis Pengaruh Marketing Mix Terhadap Keputusan Pembelian Produk Makanan Cepat Saji. Primanomics: Jurnal Ekonomi \& Bisnis, 17(1), 3344.

Wijoyo, H., Santamoko, R., Muliansyah, D., Yonata, H., \& Handoko, A. L. (2020). The Development of Affective Learning Model to Improve Student's Emotional Quotient. Journal of Critical Reviews, 7(19), 9292-9297.

Wijoyo, H. (2020). Rancang Bangun Sistem Penjualan pada CV. Sukses Karya Abadi Berbasis Web. Jurnal Ilmu Komputer dan Bisnis, 11(1), 2306-2319.

Wijoyo, H. Perancangan Sistem Informasi Administrasi pada Quality Fresh Laundry Pekanbaru. JS: Jurnal Sekolah, 4(1), 27-32. 
Wijoyo, H., \& Marpaung, S. L. (2020). The Influence of Quality Information and Reputation Of TIX ID Application Toward the Interest of Purchase Tickets Online in XXI Cinema Ciputra Seraya Mall Pekanbaru City. Jurnal Suluh Pendidikan, 8(2), 9-21. https://doi.org/10.36655/jsp.v8i2.275

Wijoyo, H. (2020). Socialization Of The Accreditation Asessment System (SISPENA) Of The National Accreditation Board For Early Childhood Education (PAUD) And Non Formal Education (PNF) In Bengkalis, Riau Province. Jurnal Humanities Pengabdian Kepada Masyarakat, 1(1), 103-111.

Yahya, M. ., \& Wijoyo, H. (2020). Developing School Information Program: Integrated Management System based on Character Value at SMP Negeri 9 Tapung. International Journal of Asian Education, 1(3), 179-186. https://doi.org/10.46966/ijae.v1i3.70

Yonata, H. Kepuasan Mahasiswa Program Studi Pendidikan Agama Buddha terhadap Pelayanan Teknologi dan Sistem Informasi Perguruan Tinggi Keagamaan Buddha di Tangerang.

Yonata, H. (2020). Peran Kesadaran/Sati terhadap Minat Baca Belajar Peserta Didik di SMB Trisaranagamana. Jurnal Ilmu Agama dan Pendidikan Agama Buddha, 2(1), 25-34. 